\title{
Reflexões sobre o viver e a politização das práticas de consumo.
}

\section{Reflections on living and the politicization of consumption practices.}

\author{
Daniela Duarte Dias ${ }^{1}$ \\ Pedrinho Arcides Guareschi \\ Inês Hennigen ${ }^{3}$
}

Resumo: Nas últimas décadas, tem acontecido um aumento nos padrões de consumo de forma global, acompanhado do aumento da poluição, da exploração dos bens naturais e a constituição de um modo de vida tomado pelo excesso de trabalho e pelo endividamento econômico. Esse artigo é resultado parcial de uma pesquisa de doutorado e teve como objetivo visibilizar como grupos com estilos de vida e de trabalho alternativos a modos massificados de viver relacionavam-se com o consumo. Problematizaremos o aspecto da individualização das responsabilidades sobre os problemas ambientais, crítica apontada por um dos grupos participantes. Ainda que refletir e modificar as práticas de consumo não acabe com os problemas ambientais, o fato de tomar para si as preocupações em relação ao planeta que habitamos pode viabilizar relações menos massificadas com a própria vida.

Palavras-chave: práticas de consumo; politização; modos de vida.

Abstract: In the last decades, an increase in globally consumption patterns took place, followed by increased pollution, exploitation of natural resources and

1 Faculdade de Integração do Ensino Superior do Cone Sul (FISUL). Garibaldi, RS, Brasil. E-mail: danieladdias@yahoo.com.br

2 Universidade Federal do Rio Grande do Sul. Porto Alegre, RS, Brasil.

E-mail: pedrinho.guareschi@ufrgs.br

3 Universidade Federal do Rio Grande do Sul. Porto Alegre, RS, Brasil. E-mail: ineshennigen@gmail.com 
a constitution of a lifestyle dominated by an excess of labor work and economic debt. This article presents partial results of a research aimed at making visible how groups with lifestyles and labor practices alternative to consumption practices. Aspects related to individualization of responsibility related to environmental problems, as criticized by some respondents of the research, are problematized. Although reflection and modification of consumption practices are not total response to environmental problems, the fact of being concerned with our planet make possible the emergence of less massed relations in our lives.

Keywords: consumption practices; politicization; lifestyle. 


\section{Introdução}

O consumo é uma atividade humana que se modifica ao longo da história (BAUMAN, 2008; BARBOSA, 2010). Dessa forma, não podemos compreender o consumo como algo homogêneo ou que serve apenas para suprir necessidades. Para Castro (2014, p. 60), "o consumo deve ser entendido como o resultado de conjunto de práticas sociais e culturais fortemente relacionados às subjetividades dos atores e ao grupo social ao qual pertencem". Quando nos referimos ao termo "consumo", estamos incluindo numa mesma esfera diferentes ações, pois, ao consumir algo, estamos nos comunicando, expressando um "estilo de vida, uma maneira de ser e agir" (CASTRO, 2014, p. 61). Para expressar melhor essas diferenças, optamos por utilizar o termo/conceito "práticas de consumo" e empregamos o termo "consumo" quando nos referimos à generalização dessas diferentes práticas sociais e culturais.

Nas últimas décadas, tem acontecido um aumento nos padrões de consumo de forma global, acompanhado de alguns efeitos, como o incremento da poluição, o avanço da exploração dos bens naturais e a constituição de um modo de vida tomado pelo excesso de trabalho e pelo endividamento econômico, entre muitos outros. Ao mesmo tempo, têm aumentado as preocupações com relação aos "limites do modelo de expansão capitalista" e seus efeitos, trazendo como pauta "as dimensões éticas e propriamente políticas das práticas de consumo [...]” (CASTRO, 2014, p. 68).

Essa relação entre consumo e problemas ambientais tem levado algumas pessoas a se responsabilizarem por suas práticas de consumo, modificando-as. Alguns militantes de movimentos sociais, grupos ativistas e também pessoas que não se organizam politicamente em grupos têm deixado de consumir produtos e/ou serviços, fazendo boicotes a marcas e/ou empresas ou simplesmente não consumindo algo que consideram supérfluo. Deixar de consumir determinados produtos ou passar a consumi-los torna-se uma ação mais refletida, pois passa a considerar: a origem de sua produção, o tipo de "relação trabalhista" existente na sua confecção, o fato de ter sido transportado por grandes 
distâncias, a posição política da empresa que produz (envolvimento em guerra, corrupção, crimes ambientais), o uso de agrotóxicos no cultivo dos alimentos etc.

Não seria possível afirmar que todas as pessoas que praticam essas ações de recusa ao consumo de determinados produtos o façam como estratégia de luta contra "o Capital". Podemos pensar que são formas de manifestar indignação em relação aos efeitos de certo tipo de produção e de consumo no planeta e na vida das pessoas, seja pela crítica à invasão de espaços privados (modificando hábitos de consumo) e/ou apropriação de espaços públicos por grandes empresas. Tais ações são formas de lutar pela própria vida, pois, ao se oporem a determinadas práticas de consumo, esses sujeitos inventam outros caminhos para seu modo de vida. Ao evidenciar essas práticas, podemos escutar outras vozes, visibilizando outros modos de habitar a Terra.

O tema do consumo vem sendo relacionado aos problemas ambientais há algumas décadas. Os noticiários de televisão informam sobre o aquecimento global, assunto ainda controverso, pois há quem afirme que o aquecimento global seria um evento natural. Conforme relatório do Painel Intergovernamental sobre Mudanças Climáticas (cuja sigla em inglês é IPCC) de 2013, o aquecimento global é um evento provocado pelo ser humano, devido às atividades industriais (NASSIF, 2014). O IPCC é um órgão criado pelo Programa das Nações Unidas para o Meio Ambiente (PNUMA) e pela Organização Meteorológica Mundial (OMM) e reúne cientistas e especialistas do mundo inteiro, que produzem seus relatórios a partir de análises de pesquisas (WOLFFENBUTTEL, 2007).

A questão da crise ambiental, até a década de 1970, era relacionada aos países em desenvolvimento devido ao fato de haver um grande crescimento populacional desorganizado, produzindo impactos sobre o meio ambiente (PORTILHO, 2005). A partir daquela década, outro discurso ganhou relevância, relacionando a questão dos problemas ambientais ao modo de produção utilizado pelos países desenvolvidos, pois consumiam mais recursos naturais e energia e, consequentemente, 
produziam mais poluição (PORTILHO, 2005). O argumento de que os problemas ambientais eram de responsabilidade do modo de produção utilizado foi sendo incorporado e impactou o setor produtivo a partir da pressão exercida pelos governos, pelo "estabelecimento de novas normas e exigências ambientais, por pressão dos movimentos ambientalistas através de denúncias, manifestações e boicotes - e ainda por iniciativa dos próprios empresários que se apropriaram do discurso ambiental" (PORTILHO, 2005, p. 2).

Foi em meados da década de 1990 que as discussões sobre o consumo responsável e a relação do consumo com o meio ambiente começaram a ganhar alguma expressão, ainda que de forma periférica, coincidindo com as denúncias sobre a crise climática (FONTENELLE, 2010). Para Portilho (2005), a Conferência Rio 92 e os documentos produzidos naquele momento, como a Declaração do Rio, a Agenda 21 e o Tratado das ONGs, influenciaram essa mudança no debate, deslocando a culpabilização dos modos de produção para os modos de consumo. Essa torção na discussão sobre os problemas ambientais, "coincide com - e pode ser explicado a partir de - uma tendência de mudança paradigmática do princípio que estrutura e organiza a sociedade, o qual também passa da produção para o consumo" (PORTILHO, 2005). Assim, vê-se, na sequência, que o relatório do IPCC de 2007 e o documentário Uma verdade inconveniente (2006), apresentado por Al Gore, ex-vice-presidente dos Estados Unidos, responsabilizam as pessoas por suas escolhas ao relacionarem o aquecimento global às atividades humanas (FONTENELLE, 2010).

Este artigo é resultado parcial da tese de doutorado intitulada Consumos e os modos de vida: problematizações sobre a estilística da existência e os modos de consumir, ${ }^{4}$ da primeira autora. A pesquisa teve como objetivo visibilizar como grupos com estilos de vida e de trabalho alternativos a modos massificados de viver relacionavam-se com o consumo; para tanto, utilizamos a cartografia como orientação metodológica e acom-

4 Tese apresentada ao Programa de Pós-graduação em Psicologia Social e Institucional para a obtenção do título de doutora em Psicologia Social e Institucional da Universidade Federal do Rio Grande do Sul. 
panhamos quatro grupos da cidade de Porto Alegre e um grupo de Nova Santa Rita, região metropolitana de Porto Alegre, no Rio Grande do Sul. Ao fazer referência a modos massificados de viver, não estamos falando em um processo fordista/taylorista de produção e da consequente massificação de determinados hábitos de consumo, mas de uma vida pouco reflexiva, de um pensamento que faz poucos desdobramentos sobre sua relação com o mundo em que vive.

As práticas de consumo comunicam, evidenciam marcas que expressam algo sobre a relação dos sujeitos com o mundo. Para Douglas e Isherwood (1990, p. 88), o consumo tem a capacidade de dar sentido ao mundo, o que "supõe interpretar a sensibilidade deste mundo". No seu entendimento, os bens são acessórios ritualísticos, sendo que o consumo é um ritual, "os bens perecem ou são consumidos, porém isto é apenas uma pequena parte do processo total de consumo" (DOUGLAS; ISHERWOOD, 1990, p. 91). Dessa forma, pensar como nos relacionamos com o consumo é refletir também sobre como nos comunicamos com o mundo em que vivemos.

Estudar as práticas de consumo, para Castro (2014, p. 62-63), significa analisar "de que modo os bens funcionam como linguagem, comunicando sinais de distinção e classificação em um meio social altamente mediado pelos signos do consumo". Significa também refletir sobre as singularidades "dos modos de apropriação de cada grupo social, que funciona segundo regras próprias de atribuição de sentido a produtos, serviços, marcas e afins" (CASTRO, 2014, p. 63), além de dar subsídios para as análises sobre o consumidor do ponto de vista mercadológico.

Ao estudar as singularidades nas relações com o consumo de diferentes grupos durante a pesquisa de doutorado, foi possível perceber que os modos de consumo de cada grupo expressavam certos modos de vida. O primeiro grupo acompanhado foi a Cambada de Teatro em Ação Direta Levanta Favela, que faz teatro de rua. O segundo foi a Pedal Express, uma cooperativa de ciclistas que presta serviços de entregas. $\mathrm{O}$ 
terceiro foi a Cooperativa de Consumo, uma parceria entre um grupo de assentados do Movimento dos Trabalhadores sem Terra (MST) que plantam produtos orgânicos e o Ateneu Libertário A Batalha da Várzea, um grupo libertário que faz a relação de venda e entrega dos produtos na cidade. O quarto grupo participante foi o Coletivo Até o Talo, grupo que cozinha alimentos veganos 5 e vegetarianos, vendendo-os em eventos públicos e na própria casa.

Cada grupo foi acompanhado por um mês em suas atividades cotidianas (com um ou dois encontros por semana), seguido de mais dois encontros (um por semana) específicos para discutir a pergunta da pesquisa: "como vocês se relacionam com o consumo?". Os registros foram feitos em diários de campo, totalizando 100 páginas. Como forma de restituição e fecho do processo, foi feito um encontro com todos os grupos para socializar o que já havia sido sistematizado sobre os materiais de pesquisa. Nesse dia, utilizamos um gravador e contamos com a participação de uma colega do grupo de pesquisa para auxiliar nos registros. O acompanhamento aos grupos aconteceu entre maio de 2013 e maio de 2014, totalizando 12 encontros com o grupo de teatro, oito com a cooperativa de ciclistas, oito com a cooperativa de consumo e oito com o grupo de culinária vegana e vegetariana. Os nomes dos grupos não foram alterados a fim de manter a relação de coautoria com os participantes. Os grupos consentiram e incentivaram a utilização de seus nomes; entretanto, os nomes dos sujeitos individuais são fictícios.

A partir do acompanhamento, observamos algumas características que cada grupo apresentava em suas práticas de consumo. Para a análise na pesquisa, destacamos apenas uma característica nas suas relações com o consumo. Assim, por exemplo, com a Cambada de Teatro em Ação Direta Levanta Favela, destacamos o fato de não aceitarem patrocínio de empresas, de não tornarem-se um produto vendável. Com a Pedal Express, destacamos as problematizações sobre os modos de resistência em relação ao consumo, mais especificamente em relação ao

5 A expressão "vegano" se refere tanto a alimentos como a pessoas que, além de não consumirem carne, também não utilizam nenhum produto de origem animal ou mesmo testado em animais. 
uso da bicicleta (o que seria resistir nesse âmbito?). Com a Cooperativa de Consumo, destacamos a solidariedade em suas relações (com a comunidade onde vivem, com os grupos com que se relacionam e com os compradores de seus produtos), buscando menos impessoalidade, maior proximidade.

\section{Individualização ou politização?}

Neste artigo, serão expostas as análises em relação ao Coletivo Até o Talo, e a característica que destacamos foi a crítica à individualização das responsabilidades sobre os problemas relacionados ao meio ambiente. O Coletivo Até o Talo tem práticas de consumo mais reflexivas, procuram consumir de forma a minimizar os efeitos dessa atividade no meio ambiente e de forma a não viver uma vida voltada para o trabalho e o consumo de bens e objetos. Entretanto, acreditam que os grandes responsáveis pela degradação do meio ambiente e pelo consumo de bens naturais sejam os grandes empresários, o agronegócio e a relação que esses setores têm com os governos.

O Coletivo se organiza de forma autogestionária; no momento da pesquisa, quatro pessoas estavam participando de forma mais ativa, todos tinham outras atividades remuneradas (nenhuma atividade formal), apenas um vivia exclusivamente do trabalho do Coletivo. Entre as atividades desenvolvidas estavam: produção de doces e salgados para eventos (festas, feiras, shows etc.) e encomendas; produção de marmitas congeladas para entregas; jantas no espaço em que residem e oficinas de culinária. O Coletivo produz comida vegana e vegetariana com baixo custo e de forma saudável, além de divulgar informações sobre esse tipo de alimentação. Entre as formas encontradas para produzir comida com baixo custo estão: utilização de plantas alimentícias não convencionais (PANC) encontradas em terrenos baldios na cidade e/ou plantadas por 
eles em casa; aproveitamento de partes de alimentos, como cascas de frutas e legumes; utilização de alimentos de forma não convencional, como o "queijo" feito de batata e a almôndega de feijão; recicle, que é a atividade de ir ao final de feiras modelo e recolher alimentos que seriam jogados fora para fazerem seu reaproveitamento.

Esse estilo de vida não é algo necessariamente novo; existe um movimento chamado freegans, ${ }^{6}$ que teve início nos Estados Unidos na década de 1990 e que se disseminou para outros países, inclusive o Brasil. Esse movimento é composto por pessoas que adotam um estilo de vida baseado no consumo mínimo, contestam o desperdício e “apoiam a comunidade, a generosidade, o interesse social, a liberdade, e a ajuda mútua, ao contrário da atual sociedade baseada em materialismo, apatia moral, competição, conformismo e cobiça" (O QUE É, 2016). Inspirados nas lutas antiglobalização e em grupos como Food Not Bombs, ${ }^{7}$ eles utilizam como estratégia o boicote ao consumo por acreditarem que a compra de quaisquer produtos de corporações prejudicará o meio ambiente e/ou os animais e/ou os direitos humanos. Para os freegans, em uma economia baseada na produção em grande escala, "movida pelo lucro, exploração de animais, de humanos e da terra, essa exploração acontece em todos os níveis de produção (desde a aquisição da matéria-prima, à produção e ao transporte) e em praticamente quase todos os produtos que compramos" (O QUE É, 2016). Logo, a alternativa que empregam é reutilizar produtos utilizados por outras pessoas, ou seja, eles coletam do lixo: móveis, eletrodomésticos, livros, CDs, alimentos, roupas, entre outros. Entre os princípios dos freegans estão: "diminuição do desperdício"; "trabalhar menos"; "recuperação do que é desperdiçado"; "retorno ao natural", através da construção de hortas comunitárias, jardinagem, colheita silvestre; "moradia livre de aluguel", através de ocupações (squat); “transporte ecológico”, sempre que possível (O QUE É, 2016).

6 São os participantes do freeganismo, a palavra freegan é a junção da palavra inglesa free com a palavra vegan.

7 Coletivos independentes que distribuem alimentação vegana de forma gratuita em protesto contra a guerra. 
O Coletivo Até o Talo não se insere no movimento freegan, mas compartilha com ele algumas características, revelando que há diferentes grupos de pessoas que buscam consumir o mínimo possível e trabalhar menos. Entretanto, o Coletivo tem sua própria singularidade, e seus membros revelam não acreditar que suas práticas de consumo minimizarão os problemas do meio ambiente. Relacionam os problemas climáticos, a poluição do ar, a contaminação das águas, o esgotamento/ devastação dos recursos naturais, o desmatamento das florestas etc. ao modo como nossa sociedade tem se relacionado com o consumo. Ao falarem sobre os problemas ambientais, distinguem os agentes poluidores, pois acreditam que os grandes responsáveis pela poluição do meio ambiente não são os sujeitos de forma individual, mas as empresas e o agronegócio - por utilizarem mais recursos energéticos e poluírem o meio ambiente, produzindo maiores impactos - e também os governos, por participarem e possibilitarem essa relação predatória.

Para o grupo, há certa culpabilização dos indivíduos e de seu modo de vida que se faz presente principalmente nos meios de comunicação, como televisão, rádios e jornais, ao falarem sobre as questões ambientais. A culpabilização dos indivíduos é apontada por Fontenelle (2010) como um dos atravessamentos do discurso do consumo responsável, uma vez que é oferecida aos consumidores a opção de comprar produtos de empresas que tenham maiores cuidados em relação ao meio ambiente. Assim, cada indivíduo pode escolher comprar ou não de empresas poluidoras do meio ambiente, expressando a ideia de um sujeito que governa a si mesmo. Para Fontenelle (2010), esse discurso, que ganhou expressão na década de 1990, apesar de marcar diferenças, demanda discussões pois responsabiliza os sujeitos por suas práticas.

Essa responsabilização dos sujeitos é veiculada pelos meios de comunicação, conforme Fontenelle (2010, p. 216): “é possível visualizar tal discurso na mídia em geral, na mídia de negócios, em revistas específicas sobre sustentabilidade e meio ambiente, em atuações de ONGs (Organizações não Governamentais) e fundações empresariais e no marketing das grandes marcas". Para a autora, é gerado um sentimento de angústia 
nos sujeitos por terem que responder por algo que ultrapassa seu entendimento sobre o assunto. Esse sentimento será o "fermento para o novo grande produto do capitalismo contemporâneo - a segurança - que, em nova roupagem, vende redenção como mercadoria" (FONTENELLE, 2010, p. 218), ou seja, o consumo responsável. O consumidor é responsável pelo "governo de si mesmo" no discurso do consumo responsável:

[...] supondo ou requerendo um sujeito racional, reflexivo, ciente dos seus atos e responsável por eles. Assim, tais discursos podem ser inseridos dentro da temática da "gestão do eu", em que está explícita uma proposta de "liberdade de escolha" e, consequentemente, de uma responsabilidade pessoal pelos atos praticados (FONTENELLE, 2010, p. 220).

O discurso da gestão do eu culpabiliza o indivíduo por ações que não são apenas individuais. Dessa forma, o sujeito é capturado a partir dessa responsabilização e pode se engajar em um modo de vida mais saudável, que também é vendido pela mídia como sendo o modo mais adequado de viver, a partir de um consumo dito mais saudável. Fontenelle (2012), em sua pesquisa sobre a mídia de negócios, na qual analisou a revista brasileira Exame e a revista britânica The Economist entre 1996 e 2007, definiu o consumo saudável como uma das categorias de análise. Nesse estudo, percebeu que as preocupações sobre o tema não estavam relacionadas ao meio ambiente, mas sim à "vida equilibrada visando o bem-estar físico e mental para o rendimento do homem no trabalho" (FONTENELLE, 2012, p. 146). Ao buscar compreender como o discurso do consumo saudável era tratado na revista Exame, especificamente, observou que era visto como uma oportunidade de negócios; por exemplo, a ideia de empreender "é enaltecida a partir da narração de casos de sucesso de inventores de shakes e bebidas gasosas diets, sanduíches naturais entre outros" (FONTENELLE, 2012, p. 147). Nas análises de algumas reportagens da revista, o consumo saudável foi observado como uma forma de investimento e o corpo, como a forma de empreender (FONTENELLE, 2012). O debate sobre consumo saudável ficava, assim, resumido a possibilidades de negócios. 
Não podemos desconsiderar as contribuições que o debate sobre o consumo responsável pelo meio ambiente possibilita ao focalizar outros pontos para a análise do problema. Portilho (2005) faz uma distinção entre o que seria uma responsabilização das ações dos sujeitos em relação ao meio ambiente - através do consumo verde - e a politização dos modos de consumir - a partir da ideia do consumo sustentável. O consumidor verde é aquele que, em seu "poder de escolha", opta por produtos que não agridam o meio ambiente, dando enfoque às ações individuais. Entretanto, a ideia de consumo verde teria limitações, individualizando a responsabilidade, deixando de lado a compreensão sobre a cultura do consumo, dando pouco enfoque aos processos de distribuição e produção e provocando uma transferência da atividade regulatória, "do Estado para o mercado, através de mecanismos de autorregulação; e do Estado e do mercado para o cidadão, através de suas escolhas de consumo" (PORTILHO, 2005, p. 3). Além disso, a autora ressalta não ser verdade que, a partir de informações sobre os problemas ambientais, os consumidores optem por adquirir produtos que não prejudiquem o meio ambiente - de fato, o consumo verde acabou por incrementar um mercado verde para pessoas que podem pagar por tais mercadorias (PORTILHO, 2005).

Por outro lado, o consumo sustentável surge como uma proposta de superação coletiva dessas limitações a partir da criação de políticas que regulem a produção e o consumo, deixando, dessa forma, de focar somente em soluções no plano tecnológico, comportamental ou econômico (PORTILHO, 2005). Um exemplo disso seria investir em ações que melhorem o transporte público coletivo, o que depende de políticas públicas e da compreensão de que não será alargando as vias públicas que se construirá uma cidade melhor.

Essas práticas de consumo mais politizadas, mais responsáveis, necessitam ser mais bem estudadas. Estudos que possam visibilizar as diversas formas de resistência, de recusa e/ou de oposição a determinados modos de consumo. Para além da aspiração ou da luta por construir um modo de vida mais sustentável, está também em questão a luta por valores 
solidários e éticos para com outros seres humanos e para com o próprio planeta Terra.

Se, por um lado, os sujeitos têm sido culpabilizados por seus modos de consumo e levados a rever seus modos de vida, por outro, podemos pensar que há sujeitos, individuais ou coletivos, que, por se rebelarem contra o modo de vida mais massificado, tomam para si responsabilidades em relação ao mundo, politizando um espaço que antes era visto como privado. Não acreditamos que o consumidor seja o sujeito que transformará a sociedade, entretanto, é possível:

[...] considerar a possibilidade de politização e ambientalização da esfera privada, considerado-a uma necessária extensão das novas práticas políticas. Se as propostas de mudança dos padrões de consumo fazem parte do projeto e da utopia da "sociedade sustentável", os consumidores - individuais ou organizados - podem ser pensados como um dos portadores desse projeto, construindo novas formas de ação política e fortalecendo a cidadania e o interesse pelo espaço público (PORTILHO, 2005, p. 10).

É nessa perspectiva que o Coletivo Até o Talo coloca para si a tarefa de desconstruir a relação que aprenderam a ter com o consumo e de fazer um trabalho sobre si mesmo para criar outra relação, inventar outras práticas de consumo, escapando da lógica em que as críticas aos efeitos dos modos de consumir se transformam em uma possibilidade de negócios. Ao mesmo tempo, afirmam não terem a ilusão de viver "fora do sistema", apenas buscam viver de forma a experienciar o tipo de sociedade que almejam, ou seja, uma sociedade mais justa, preocupada com o planeta, com os animais e com os outros seres humanos. Segue abaixo um diálogo que expressa essa ideia:

Letícia: O capitalismo joga para o indivíduo a responsabilidade, mas as empresas consomem por todas as pessoas. Não tem nenhuma mudança nisto, se todas as pessoas parassem de utilizar recursos naturais não mudaria nada na sociedade. Mas individualmente, a gente se satisfaz vivendo deste jeito. Camila: Se satisfaz reproduzindo aquilo que a gente acredita. Letícia: A gente é uma experiência da sociedade que a gente projeta (DIÁRIO DE CAMPO, 20 maio 2014). 
Os participantes expressam que os problemas em relação ao meio ambiente estariam relacionados à lógica de vida voltada para o consumo. Ao afirmar que se satisfaz fazendo aquilo em que acredita, Camila expressa fazer de sua vida uma experiência do mundo que gostaria de viver, satisfazendo-se em colocar em prática as escolhas que acredita serem as melhores para si e para o mundo. Compreende que suas práticas em relação ao consumo não solucionarão os problemas em relação ao meio ambiente, ainda que possam amenizar uma ou outra situação. Ao economizar água, reaproveitar alimentos, andar de bicicleta, customizar roupas, reutilizar objetos, Camila e seus companheiros do grupo se constituem enquanto sujeitos e suas práticas sustentam seus princípios. Assim, comunicam seu modo de vida a partir de suas práticas de consumo. Ao expressarem o que pensam a partir do modo como se vestem, como se alimentam, como se locomovem, como habitam a cidade, como se relacionam com outras pessoas etc., comunicam suas escolhas sobre o viver, o que faz e traz sentido a sua existência.

Entretanto, buscar colocar em prática seus próprios princípios e politizar um espaço até então tido como privado (PORTILHO, 2005) exige um grande esforço. Para construir essa politização do ambiente privado, os participantes do Coletivo Até o Talo afirmam que é necessário um trabalho constante sobre si mesmo para desconstruir aquilo que aprenderam em relação a práticas de consumo. Para Camila, “desconstruir não é negar o consumo, porque a gente vive nesse sistema, não há como ficar fora. Desconstruir é um processo de busca por mais autonomia neste sistema" (DIÁRIO DE CAMPO, 20 maio 2014). Para o Coletivo Até o Talo, desconstrução de práticas de consumo passa pela busca por uma relação de maior autonomia em relação aos objetos de consumo no capitalismo. Para tanto, buscam aprender as atividades de construir, costurar, cozinhar, plantar etc. de forma mais autônoma e criticam o modo de vida no capitalismo - que produz um distanciamento entre quem produz algo e quem consome e engendra um modo de vida marcado por um movimento cíclico entre trabalho, compra de objetos, endividamento, descarte de objetos. 
Para Rodrigo, esse modo de vida aprisiona as pessoas, elas "ganham um cartão de crédito do banco e acabam se endividando, adquirem dívidas de financiamentos que serão pagos a longo prazo, desta forma, a pessoa não vai poder largar o emprego por causa destas dívidas" (DIÁRIO DE CAMPO, 27 maio 2014). Para Hennigen (2010), há uma relação de reciprocidade, de produção mútua entre crédito e consumo, ou sociedade de consumo, pois uma pessoa pode adquirir bens e serviços ainda que não tenha como pagar. Pode-se pensar que o crédito tanto democratiza o acesso ao consumo como pode produzir grandes problemas ao sujeito quando utilizado sem planejamento, "adquirido de forma excessiva e irrefletida, ou se suceder algum 'acidente de vida' ao endividado, dentre outros fatores” (HENNIGEN, 2010, p. 1.191).

O endividamento, para Hennigen (2010, p. 1.189), "vai sendo administrado. Ou não. Quando as dívidas ultrapassam as possibilidades do orçamento dos consumidores, ocorre o que se passou a nomear superendividamento". Para pagar esse endividamento econômico, os sujeitos não podem deixar de trabalhar, sendo a dedicação intensiva ao trabalho uma das características esperadas de um integrante da sociedade de consumidores (BAUMAN, 2008). Conforme Bauman (2008, p. 17), "o empregado ideal seria uma pessoa sem vínculos, compromissos ou ligações emocionais anteriores, e que evitem estabelecê-los agora; uma pessoa pronta para assumir qualquer tarefa que lhe apareça [...]”. Nessa lógica, Letícia explica que o consumo, no capitalismo, gera endividamento econômico, as pessoas "se endividam por comprar coisas que não vão durar” (DIÁRIO DE CAMPO, 27 maio 2014).

As críticas do Coletivo, assim como as de Bauman (2008), são em relação ao trabalho demasiado, que deixa pouco espaço para o lazer, para a reflexão, para o convívio com as pessoas e que serve para adquirir objetos que terão um curto período de duração e logo serão descartados. Para Letícia, é necessário resgatar a "posição de não ser só consumidor, todo mundo é educado só para consumir. É o que queremos resgatar - a autonomia - fugir desta ideia de que toda pessoa é somente um consumidor em potencial" (DIÁRIO DE CAMPO, 20 maio 2014). Daí 
a importância de pensarmos que politizar as práticas de consumo pode também nos levar a refletir sobre o que fazemos, não necessariamente a mudar o mundo, mas a dizer que fazemos parte deste mundo.

Para Rodrigo, "cada vez mais as pessoas são só produtoras de coisas simbólicas, porque ninguém mais sabe fazer as coisas com as próprias mãos" (DIÁRIO DE CAMPO, 27 maio 2014). A importância de fazer "as coisas com as próprias mãos" estaria em ter mais autonomia sobre a própria vida e conhecer aquilo que se consome, de sair da posição de ser apenas consumidor. Os participantes afirmam que, nessa busca por autonomia, é necessário aprender a lidar com as próprias necessidades e deixam evidente que não há um "fora do sistema capitalista”, pois todos têm "contas a pagar", e que a negação do modo de vida no capitalismo pode trazer muitas amarras, impossibilitando a reflexão sobre o vivido. Ao negar que se vive no mundo capitalista, imaginando que haveria um "fora", o sujeito criaria estratégias de vida e de resistência em desacordo com sua realidade, criaria ilusões sobre o seu próprio fazer. Expressam que é necessário justamente refletir sobre essa realidade para conseguir produzir práticas de consumo com maior autonomia, levando em conta suas necessidades. Para Camila e Letícia:

[...] não é possível escapar do capitalismo, dizer que fazemos isto seria uma atitude hipócrita, já que precisamos pagar aluguel, por exemplo. [...] Até tu arrumar outro jeito, tu está dentro. Mesmo para que tu ocupes uma terra, tu precisas de capital para começar a produzir nela, para sair do capitalismo tu precisa ter capital (DIÁRIO DE CAMPO, 20 nov. 2014).

Entretanto, em suas práticas, elas evidenciam ser sim possível viver de outra forma, ainda que dentro do sistema capitalista: seus modos de vida expressam justamente que não vivemos uma sociedade na qual todos têm uma vida voltada para o consumo, pois há pessoas que tentam colocar em suas práticas valores éticos, neste caso, nas práticas do consumo. E nessa busca por experienciar esse mundo que almejam, constituem a si mesmos e evidenciam outros modos de viver que podem inspirar outras pessoas. 


\section{Considerações finais}

Compreender as práticas de consumo como comunicação, sinais que expressam algo sobre a cultura, escolhas ou impossibilidades de escolhas nos auxilia a ampliar o olhar sobre nossa própria relação com o mundo. Ao perceber que as práticas de consumo expressam modos de vida, é possível lançar um olhar mais atento aos grupos sociais, empreendendo análises menos totalizantes sobre o consumo, visibilizando as singularidades existentes.

Essas problematizações sobre as relações do sujeito consigo mesmo e com o mundo em que vivem expressam a constituição de sujeitos mais reflexivos no âmbito pessoal. Mas também apontam que a incorporação de novas práticas no âmbito do consumo pode manifestar outras formas de participação na esfera pública. É preciso compreender que as práticas de consumo não são práticas individuais, ainda que expressem também algo sobre um sujeito individuado. As práticas de consumo, ao exercerem seu papel de comunicação, visibilizam hábitos culturais, expressam modos de vida, apontam reivindicações políticas dos sujeitos sobre o mundo. Dessa forma, a inclusão de "valores como solidariedade, ética e responsabilidade nos discursos, escolhas e práticas de consumo, conforme proposto por alguns movimentos sociais, exige de sociólogos e antropólogos uma revisão no próprio conceito de sociedade e cultura de consumo [...]" (PORTILHO, 2009, p. 203).

O Coletivo Até o Talo evidenciou que politizar as práticas de consumo não é o mesmo que aceitar a culpabilização dos indivíduos sobre os problemas ambientais. Ainda que refletir e modificar nossas práticas de consumo não acabe com os problemas ambientais, o fato de tomar para si as preocupações em relação ao planeta que habitamos pode viabilizar relações menos massificadas com a própria vida. Saber de onde vêm os alimentos que comemos, como são feitos, quem os produz, expressa a vontade de construir um modo de vida menos impessoal, mais acolhedor. Ao mesmo tempo, politizar as práticas de consumo não leva, necessariamente, a uma individualização da responsabilidade sobre os problemas ambientais, ainda que a culpabilização exista e circule de 
forma mais ou menos marcada em diferentes espaços midiáticos. Essa politização pode levar ao engajamento dos sujeitos em relação ao mundo em que vivem, refletindo sobre suas práticas, visibilizando outras possibilidades de habitar o planeta.

\section{Referências}

BARBOSA, L. Sociedade de consumo. 3. ed. Rio de Janeiro: Zahar, 2010.

BAUMAN, Z. Vida para consumo: a transformação das pessoas em mercadorias. Rio de Janeiro: Zahar, 2008.

CASTRO, G. G. S. Comunicação e consumo nas dinâmicas culturais do mundo globalizado. pragMATIZES - Revista Latino-americana de Estudos em Cultura, Rio de Janeiro, ano 4, n. 6, p. 58-71, mar. 2014. (Semestral). Disponível em: http://www.pragmatizes.uff.br/revista/index.php/ojs/article/view/55. Acesso em: 30 maio 2016.

DOUGLAS, M.; ISHERWOOD, B. El Mundo de los Bienes: Hacia una antropología del consumo. México: Editorial Grijalbo, 1990.

FONTENELLE, I. A. Consumo como investimento: a produção do consumidor saudável pela mídia de negócios. Comunicação, mídia e consumo, São Paulo, v. 9, n. 24, p. 133-152, maio 2012. Disponível em: http:/gvpesquisa.fgv.br/sites/gvpesquisa.fgv.br/ files/arquivos/fontenelle_-_consumo_como_investimentos_a_producao_do_consumidor_saudavel_pela_midia_de_negocios.pdf. Acesso em: 30 maio 2016.

O fetiche do eu autônomo: consumo responsável, excesso e redenção como mercadoria. Psicol.Soc., Florianópolis, v. 22, n. 2, p. 215-224, ago. 2010. Disponível em: http:// www.scielo.br/scielo.php?script=sci_arttext\&pid=S0102-71822010000200002\&lng=en \&nrm=iso. Acesso em: 29 maio 2016.

HENNIGEN, I. Superendividamento dos consumidores: uma abordagem a partir da Psicologia Social. Rev. Mal-Estar Subj., Fortaleza, v. 10, n. 4, p. 1.173-1.202, dez. 2010. Disponível em: http://pepsic.bvsalud.org/scielo.php?script=sci_arttext\&pid=S1518$-61482010000400006 \& \operatorname{lng}=$ pt\&nrm=iso. Acesso em: 30 maio 2016.

NASSIF, L. Influência humana no aquecimento global é evidente, alerta novo relatório do IPCC. GGN: o jornal de todos os Brasis. 2014. Disponível em: http://jornalggn.com. br/noticia/influencia-humana-no-aquecimento-global-e-evidente-alerta-novo-relatorio-do-ipcc. Acesso em: 4 mar. 2016.

O QUE É freeganismo? FREEGAN.INFO: Strategies for sustainable living beyond capitalism. Disponível em: http://freegan.info/what-is-a-freegan/translations/o-que-e-freeganismo/. Acesso em: 30 maio 2016. 
PORTILHO, F. Consumo sustentável: limites e possibilidades de ambientalização e politização das práticas de consumo. Cad. Ebape.br, Rio de Janeiro, v. 3, n. 3, p. 1-12, 2005. Disponível em: http://www.scielo.br/scielo.php?script=sci_arttext\&pid=S1679-39512005000300005\&lng=pt\&nrm=iso. Acesso em: 30 maio 2016.

Novos atores no mercado: movimentos sociais econômicos e consumidores politizados. Política E. Sociedade, Florianópolis, v. 8, n. 15, p. 199-224, out. 2009. Disponível em: https://periodicos.ufsc.br/index.php/politica/article/view/2175-7984.2009v8n15p199. Acesso em: 30 maio 2016.

WOLFFEnBUTTEL, A. O que é? IPCC. Ipea.gov.br. 2007. Disponível em: http:// www.ipea.gov.br/desafios/index.php?option=com_content\&view=article\&id=2134:cati $\mathrm{d}=28 \&$ Itemid=23. Acesso em: 4 mar. 2016.

\section{Sobre os autores}

Daniela Duarte Dias - Atualmente trabalha na Fisul, Garibaldi - RS. Doutora em Psicologia Social e Institucional pelo Programa de Pós-graduação em Psicologia Social e Institucional da Universidade Federal do Rio Grande do Sul.

Pedrinho Arcides Guareschi - Professor convidado da Universidade Federal do Rio Grande do Sul (UFRGS) e conferencista internacional. Tem experiência na área de Psicologia, com ênfase em Psicologia Social, atuando principalmente nos seguintes temas: mídia, ideologia, representações sociais, ética, comunicação e educação.

Inês Hennigen - Professora adjunta da Universidade Federal do Rio Grande do Sul, Instituto de Psicologia, Departamento de Psicologia Social e Institucional, e do PPG em Psicologia Social e Institucional. Tem experiência na área de Psicologia, com ênfase em Psicologia Social e Psicologia e Educação. Atualmente tem se dedicado ao estudo, pesquisa e intervenção concernentes às seguintes questões: modos de subjetivação, mídia e tecnologias, relações de gênero, educação, relações de consumo, cidadania e (super)endividamento.

Data de submissão: 15/09/2016

Data de aceite: 12/12/2016 